\title{
Association of Serum Lipids, Oxidative Stress and serum Cystatin C with Prehypertension and Hypertension
}

\author{
Sumapreethi $\mathrm{A}^{1}$, Bhaskar M V², Babu K J $\mathbf{J}^{3}$, Madhulatha $\mathrm{M}^{4}$ \\ ${ }^{1}$ Dr A SumaPreethi*, Assistant Professor, ${ }^{2}$ Dr M Vijaya Bhaskar*, Professor \& Head, ${ }^{3}$ Dr K Jagadeesh Babu, Associate \\ Professor, Department of Neurosurgery, Mamata Medical College and General Hospital, Khammam, ${ }^{4}$ Dr M. MadhuLatha*, \\ Assistant Professor. *All are affiliated with Department of Biochemistry, Mamata Medical College and General Hospital, \\ Khammam, Telangana, India
}

Address for correspondence: Dr. A.SumaPreethi, E-mail: dr.venneladasari@gmail.com

\begin{abstract}
Introduction: Hypertension is the most important cardio vascular risk factor, contributing to one half of the coronary heart diseases and approximately two third of the cerebrovascular diseases. Hypertension has been recognised as one of ten (10) leading reported causes of death with about $4 \%$ of such deaths due to hypertensive complications. Cystatin $\mathrm{C}$ is independently and positively associated with the risk for hypertension. There is a mounting body of evidence which indicates reactive oxygen species (ROS) production is linked to vascular/endothelial dysfunction. With this background we assessed lipids, oxidative stress and cystatin $\mathrm{C}$ in serum of patients with essential hypertension and prehypertension. Materials and methods: Total cholesterol, Triglyceride, HDL cholesterol, LDL cholesterol, Malondialdehyde (MDA), Total antioxidant capacity (TAC) and cystatin $\mathrm{C}$ were measured in serum of subjects with essential hypertension, prehypertension and age and sex matched controls. Study groups comprised of 66 each, subjects with hypertension and prehypertension. Control group comprised of 68 healthy volunteers. Results: Mean serum levels of MDA, Cholesterol, Triglycerides and LDL cholesterol and cystatin $\mathrm{C}$ were significantly increased and TAC and HDL cholesterol levels were significantly decreased in subjects with hypertension and prehypertension compared to controls. Conclusion: Our results revealed that both hypertension and prehypertension are associated with dyslipidemia, altered oxidative status and raised serum cystatin $\mathrm{C}$ levels. Our study also suggests the continued need for early clinical detection and intervention of prehypertension to reduce adverse health consequences of hypertension and its impact.
\end{abstract}

Key Words: Prehypertension, Cystatin C,ROS, Oxidative stress, MDA, TAC

\section{Introduction}

Hypertension has been recognised as the most common cardiovascular disorder and a leading cause of disability and death in both developed and developing countries [1, 2]. One billion individuals are affected by hypertension worldwide and estimated to reach upto 1.56 billion by the year 2025[3]. In India, 31.5 million have hypertension in rural India and 34 million in urban India. Globally cardiovascular disease accounts for approximately 17 million deaths a year, nearly one third of the total. Of these, complications of hypertension account for 9.4 million deaths worldwide every year [4]. Hypertension may be defined as sustained elevation of systemic arterial pressure above $140 / 90 \mathrm{~mm}$ of $\mathrm{Hg}$. It is the level of pressure at which institution of therapy reduces related morbidity and mortality [5]. Essential hypertension is

Manuscript received: $7^{\text {st }}$ June 2014

Reviewed: $10^{\text {th }}$ June 2014

Author Corrected: $19^{\text {th }}$ July 2014

Accepted for Publication: 22 $2^{\text {nd }}$ July 2014 described as a rise in BP (arterial blood pressure) from unknown etiologies. JNC 7 report has introduced a new classification that includes the term "prehypertension" for those with BPs ranging from 120-139 $\mathrm{mmHg}$ systolic and/or 80-89 mmHg diastolic [6] (Table 1). This new designation is intended to identify those individuals in whom early intervention by adoption of healthy lifestyles could reduce BP, decrease the rate of progression of BP to hypertensive levels with age, or prevent hypertension entirely.

Dyslipidaemia, which is associated with hypertension, has been recognised as an independent risk factor for cardiovascular disease, a leading cause of disability and death [7]. The association between hypertension and dyslipidaemia is well established and both may add up to the increased susceptibility to the development of coronary heart disease. 
Table 1: JNC 7 Classification

\begin{tabular}{|l|l|l|}
\hline Blood Pressure & SBP & DBP \\
Classification & $\mathrm{MmHg}$ & $\mathrm{MmHg}$ \\
\hline Normal & $<120$ & and $<80$ \\
\hline Prehypertension & $120-139$ & or $80-89$ \\
\hline Stage 1 Hypertension & $140-159$ & or $90-99$ \\
\hline Stage 2 Hypertension & $>160$ & or $>100$ \\
\hline
\end{tabular}

Over the past decade, the role of reactive oxygen species (ROS) in the cardiovascular system has been the subject of research interest. ROS Within the cardiovascular system is associated with pathological changes observed in hypertension. Patients with hypertension demonstrate increased levels of oxidative stress byproducts together with decreased activity of endogenous antioxidants in blood [8].

Cystatin $\mathrm{C}$ is a 13-kDa protein and a member of a family of competitive inhibitors of lysosomal cysteine protease synthesized at a constant rate in all nucleated cells .Cystatin $\mathrm{C}$ appears to be a marker of cardiovascular risk, and high concentrations of circulating cystatin $\mathrm{C}$ have been shown to be consistently and strongly associated with cardiovascular outcomes in different clinical scenarios [9]. Under these circumstances, we assessed lipid profile, oxidative stress and Cystatin $\mathrm{C}$ in patients with essential hypertension, prehypertension and compared the same with age and sex matched controls.

\section{Materials and methods}

The present study has been carried out in Mamata medical college and general hospital, Khammam. 66 each, newly diagnosed subjects with essential hypertension and prehypertension as per JNC7 criteria were recruited. 68 age and sex matched healthy normotensive subjects as per JNC7 criteria were included as controls. Patients with DM (according to WHO criteria) Renal dysfunction, Renal dysfunction (serum creatinine $>1.6$ in men and $>1.1$ in women) CAD and other forms of secondary hypertension, patients on antihypertensive drugs were excluded from the study. Also smokers, alcoholics, pregnant women and women on OCPs, patients on lipid lowering drugs, antioxidant and vitamin supplements were excluded. Twelve hour fasting blood samples were collected, serum was separated and the following parameters were analyzed using standard methods.

Total cholesterol, (cholesterol oxidase/peroxidase/ACCUREX) Triglycerides (Glycerol phosphate Oxidase /peroxidase /ACCUREX), High density lipoprotein Cholesterol (HDL - C) (Phosphotungstate precipitation method/ACCUREX), Low Density Lipoprotein Cholesterol (LDL - C) Malondialdehyde (MDA) as Thiobarbituricacid reactive substances (TBARS), Total antioxidant capacity(TAC) [FRAP (Ferric Reducing Ability of Plasma) assay] Cystatin C (Latex enhanced Immunoturbidimetry/AGAPPE) were estimated using UV Spectrophotometer (Systronics).

\section{Results}

Statistical analysis was done by using one-way ANOVA (analysis of variance) followed by Student's t test.

$<0.05$ is considered significant.

Table 2: Mean \pm SD of controls, Prehypertension and Hypertension

\begin{tabular}{|c|c|c|c|c|c|c|c|c|}
\hline Group & & $\begin{array}{l}\text { T.chol } \\
\text { (mg/dl ) }\end{array}$ & $\begin{array}{l}\text { TG } \\
(\mathrm{mg} / \mathrm{dl})\end{array}$ & $\begin{array}{l}\text { HDLc } \\
(\mathrm{mg} / \mathrm{dl})\end{array}$ & $\begin{array}{l}\text { LDLc } \\
(\mathrm{mg} / \mathrm{dl})\end{array}$ & $\begin{array}{l}\text { MDA } \\
(\mathrm{nmol} / \mathrm{ml})\end{array}$ & $\begin{array}{l}\text { TAC } \\
(\mu \mathrm{mol} / \mathrm{ml})\end{array}$ & $\begin{array}{l}\text { Cystatin } \\
\text { C } \\
(\mathrm{mg} / \mathrm{L})\end{array}$ \\
\hline Control & $\begin{array}{l}\text { Mean } \pm S \\
\text { D }\end{array}$ & $\begin{array}{l}162.03 \pm 2 \\
2.12\end{array}$ & $\begin{array}{l}115.88 \pm 3 \\
7.42\end{array}$ & $\begin{array}{l}41.65 \pm 3 . \\
31\end{array}$ & $\begin{array}{l}97.24 \pm 18 \\
.87\end{array}$ & $1.69 \pm 0.51$ & $1.17 \pm 0.34$ & $0.75 \pm 0.25$ \\
\hline Pre HTN & $\begin{array}{l}\text { Mean } \pm S \\
\text { D }\end{array}$ & $\begin{array}{l}170.3 \pm 39 \\
.61\end{array}$ & $\begin{array}{l}154.93 \pm 1 \\
.42\end{array}$ & $\begin{array}{l}39.18 \pm 4 \\
67\end{array}$ & $\begin{array}{l}100.42 \pm 3 \\
3.99\end{array}$ & $\begin{array}{l}3.218 \pm 1.4 \\
2\end{array}$ & $0.76 \pm 0.3$ & $0.98 \pm 0.32$ \\
\hline HTN & $\begin{array}{l}\text { Mean } \pm S \\
\text { D }\end{array}$ & $\begin{array}{l}218.03 \pm 5 \\
2.75\end{array}$ & $\begin{array}{l}184.06 \pm 5 \\
4.26\end{array}$ & $\begin{array}{l}37.69 \pm 4 . \\
23\end{array}$ & $\begin{array}{l}143.33 \pm 5 \\
0.96\end{array}$ & $4.07 \pm 1.85$ & $0.57 \pm 0.16$ & $1.5 \pm 0.33$ \\
\hline
\end{tabular}


Mean values of Total cholesterol, Triglycerides, LDLc, MDA and Cystatin C were increased in both prehypertensives and hypertensives when compared to controls. HDLc and Total antioxidant capacity levels were decreased in both the groups when compared with control group.

Table 3: Anova Results

\begin{tabular}{|l|l|l|l|}
\hline & Parameter & F value & p value $(<)$ \\
\hline $\mathbf{1 .}$ & T. cholesterol & 19.054 & 0.0001 \\
\hline $\mathbf{2 .}$ & HDLc & 132.977 & 0.01 \\
\hline $\mathbf{3 .}$ & LDLc & 16.189 & 0.0001 \\
\hline $\mathbf{4 .}$ & TG & 14.510 & 0.0001 \\
\hline $\mathbf{5 .}$ & MDA & 24.634 & 0.0001 \\
\hline $\mathbf{6 .}$ & TAC & 37.48 & 0.0001 \\
\hline $\mathbf{7 .}$ & Cystatin C & 40.735 & 0.0001 \\
\hline
\end{tabular}

Anova is significant in all the groups.

Table 4: Multiple comparison test results

\begin{tabular}{|l|l|l|l|}
\hline \multirow{2}{*}{ Parameter } & Control vsHTN & Controls vsPre HTN & HTN and Pre HTN \\
\cline { 2 - 4 } & p value( $<$ ) & pvalue & p value \\
\hline 1. T. cholesterol & 0.0001 & 0.272 & $<0.0001$ \\
\hline 2. TG & 0.0001 & 0.003 & 0.046 \\
\hline 3. HDLc & 0.0001 & 0.018 & 0.164 \\
\hline 4. LDLc & 0.0001 & 0.635 & $<0.0001$ \\
\hline 5. MDA & 0.0001 & $<0.0001$ & 0.024 \\
\hline 6. TAC & 0.0001 & $<0.0001$ & 0.001 \\
\hline 7. Cystatin C & 0.0001 & $<0.0001$ & 0.0001 \\
\hline
\end{tabular}

All the parameters showed significance except Total cholesterol and LDLc in prehypertensives vs controls and HDLc in hypertensive vs prehypertensive group.

\section{Discussion}

Hypertension has emerged as a global health problem and is posing a health challenge by topping the list of killer diseases due to the associated target organ damage. In the present study, the mean serum cholesterol level was significantly increased in hypertensives when compared with prehypertensives and controls. Though the mean was increased in

hypertensives compared with prehypertensives, the mean difference was not significant. The mean serum triglyceride level was significantly increased in hypertensives when compared with prehypertensives and controls. The mean serum HDLc level decreased significantly in hypertensives when compared with prehypertensives and controls.

The mean serum LDLc level was significantly increased in hypertensives when compared with prehypertensives $\&$ Controls. The mean difference was statistically significant when compared between hypertensives and
Controls, hypertensives and prehypertensives. The mean difference was not significant though the mean was increased in hypertensives compared with prehypertensives. These observations are consistent with previous related studies. $[10,11]$

Dyslipidemia, a strong predictor of cardiovascular disease, causes endothelial damage, and the loss of physiological vasomotor activity that results from endothelial damage may become manifested as hypertension. Abnormal activation of renin-angiotensin system (RAS) plays a critical role in several regulatory systems implicated in hypertension pathophysiology. Firstly, the activity of the circulating and arterial wall RAS is up-regulated in hypercholesterolaemic patients [12]. Secondly, hypercholesterolaemia up-regulates angiotensin II type 1 receptor (AT1) expression, intensifying a broad range of responses to angiotensin II including vasoconstriction, salt retention and oedema [13].

Available online at: www.ijmrr.in 351 | P a g e 
More recently, a growing number of studies has indicated that hypercholesterolaemia is associated with increased circulating levels of endothelin 1 (ET-1) and enhanced activity of ET receptors, an autocrine-paracrine system directly implicated in the regulation of arterial vascular tone and sodium and water homeostasis [14]. This vasodysregulation could lead to an inability or difficulty in vasodilatation to appropriate stimuli and eventually to increased resting BP.

The mean serum MDA level was increased in hypertensives when compared with prehypertensives and controls. The mean difference was significant. The mean Total Antioxidant Capacity level was decreased in hypertensives when compared with prehypertensives and controls. The mean difference was significant. These observations are consistent with previous related studies $[15,16,17,18]$.

The ROS 'family' encompasses various molecules, which have wide-ranging and divergent effects on cellular function. There is a mounting body of evidence that indicates that ROS production is directly related to the mechanisms of vascular/endothelial dysfunction.

The recruitment of inflammatory molecules in concert with vascular oxidative stress increases endothelial permeability impairing endothelial function and exacerbating vascular damage, as seen in patients with essential hypertension [19]. Subsequent to lipid peroxidation is the formation of highly reactive intermediates, which alter cell function and generate bioactive compounds [20].

The mean Cystatin C level was significantly increased in hypertensives when compared with prehypertensives and Controls. Inflammation, associated with atherogenic changes, may be one mechanism associated with cystatin $\mathrm{C}$ and cardiovascular risk.

Inflammatory cytokines stimulate the production of lysosomal cathepsins, and increased plasma concentrations of cystatin $\mathrm{C}$, a cathepsin inhibitor, may reflect, at least inpart, an attempt to counterbalance a potentially damaging increased elastolytic activity causing hypertension.

Studies have demonstrated that human cathepsins are expressed in endothelial cells, smooth muscle cells, and macrophages, and that they are involved in the progression, the composition, and the rupture of atherosclerotic plaques [21]. This response is likely to involve the interaction of mechanisms determined genetically. Present study corroborates the observations of other studies $[22,23,24]$.

The present study revealed an association between hypertension, prehypertension and serum lipids. Two of the most prevalent and asymptomatic risk factors for CHD are hypertension and dyslipidemia and they commonly co-exist. The CHD risk in patients with comorbid hypertension and dyslipidemia is greater than the sum of CHD risks for hypertension and dyslipidemia when they occur alone.

Aggressive management of both dyslipidemia and hypertension is warranted to lower CHD risk. Our findings revealed an association between hypertension, pre-hypertension and oxidative stress markers linked to atherosclerosis process.

Thus, the identification of the underlying molecular mechanisms in pre-hypertension, which seem to include oxidative stress, may serve as an important lead for developing potentially new treatment modalities in this group of patients at risk for future cardiovascular complications.

Our study also showed an association between hypertension, prehypertension and serum Cystatin $\mathrm{C}$ levels. Patients with higher circulating cystatin $\mathrm{C}$ concentrations appear to have an increased cardiovascular risk profile, i.e., have a higher prevalence of systemic hypertension \& dyslipidemia.

Cystatin C may thus help, to identify individuals who are at increased risk for the development of CVD, and who may benefit from more "aggressive" preventive measures, such as lowering blood pressure to stringent targets and enrolment into strict monitoring programmes. To date, however, no study has evaluated therapeutic strategy based on risk stratification using cystatin $\mathrm{C}$ values. Further research is required to gain insight into the true significance of increased cystatin $\mathrm{C}$ concentrations in these various clinical settings.

Because the lifetime risk of developing hypertension is very high, a public health strategy, which complements the hypertension treatment strategy, is warranted. To prevent BP levels from rising, primary prevention measures should be introduced to reduce or minimize these causal factors in the population, particularly in individuals with prehypertension.

A population approach that decreases the BP level in the general population by even modest amounts has the 
potential to substantially reduce morbidity and mortality or at least delay the onset of hypertension. It therefore suggests the need to pursue preventive strategies in people with prehypertension.

\section{Funding: Nil}

Conflict of interest: Nil

Permission from IRB: Yes

\section{References}

1. The sixth Reports of the Joint National Committee on Detection, Evaluation and Treatment of High Blood Pressure (JNC VI). Arch Intern Med 1997; 157: 24132446. (s)

2. Classification of hypertension. Report of WHO Scientific Group, WHO Technical Report Series 1978; 657: 87-95(s)

3. Kearney, P., Whelton, M., Reynolds, K., Muntner, P., Whelton, P., \& He, J. (2005). Global burden of hypertension: analysis of worldwide data. Lancet, 365 (9455), 217-223.

4. WHO.A global brief on hypertension- Silent killer, global public health crisis. April 2013. (http://www.who.int/cardiovascular_diseases/publicatio ns/global_brief_hypertension/en/)

5. Theodore A. Kotchen, Harrison's Principles of Internal Medicine . 17th ed. New York: McGraw-Hill; 2008. Chapter 241, Hypertensive Vascular Disease; p.1549-62.

6. The seventh Report of the Joint National Committee on Detection, Evaluation and Treatment of High Blood Pressure (JNC 7), Aug 2004. ( http:/www.nhlbi.nih.gov/guidelines/hypertension/jnc7f ull.pdf)

7. Gordon H, Eugene Braunwald et.al. Harrison's Principles of Internal Medicine .15th edition; New York : McGraw--Hill 2000; . Hypertensive vascular disease; $p$. 141-1430.

8. Redon J., Oliva M.R., Tormos C., et alAntioxidant activities and oxidative stress byproducts in human hypertension. Hypertension 2003; 41:1096-1101.

9. Parikh NI, Hwang SJ, Yang Q, Larson MG, Guo CY, Robins SJ, et al. Clinical correlates and heritability of cystatin C (from the Framingham Offspring Study). Am J Cardiol 2008;102:1194-1198.
10. B.A. Bhavani, T.Padma, B.K.S.Sastry. Plasma Lipoprotein (a) levels in patients with untreated essential hypertension. Indian Journal of Human Genetics : 2003; 9( 2) : 65-68.

11. Biswas UK And Kumar A Study On Lipid Profile, Oxidation Stress And Carbonic Anhydrase Activity In Patients With Essential Hypertension. Journal of Clinical and Diagnostic Research ;2010 December 10; (4):34143420 .

12. Alderman MH, Ooi WL, Cohen H, Madhavan S, Sealey JE, Laragh JH. Plasma renin activity: a risk factor for myocardial infarction in hypertensive patients. Am J Hypertens 1997;10(1):1-8.

13. Uehara $Y$, Urata $H$, Sasaguri $M$ et al. Increased chymase activity in internal thoracic artery of patients with hypercholesterolaemia. Hypertension 2000;35:5560 .

14. Ferrario CM. Importance of the renin-angiotensinaldosterone system (RAS) in the physiology and pathology of hypertension. An overview. Drugs 1990;39(suppl 2):1-8.

15. Schiffrin EL. State-of-the-art lecture. Role of endothelin-1 in hypertension. Hypertension 1999; 34:876-81.

16. Ramón Rodrigo, HernánPrat, Walter Passalacqua.Relationship between oxidative stress and essential hypertension. Hypertension research official journal of the Japanese Society of Hypertension 2007;30(12):1159-1167.

17. Russo.C,OlivieriO,Girelli D Anti-oxidant status and lipid peroxidation in patients with essential hypertension.J Hypertens. 1998 Sep;16(9):1267-71.

18. RuiTang, Hai-taoLi, Wen-jun Ma and Shao-xianSun. Serum lipid peroxidation levels in prehypertensive patients. American Journal of Hypertension 2010; 23(1):104.

19. Xu, S., \&Touyz, R. Reactive oxygen species and vascular remodelling in hypertension: still alive. Can. J. Cardiol. 2006; 947-951.

20. Kristal, B., Shurta-Swirrki, R., \&Chezar, J. Participation of peripheral polymorphonuclear leukocytes in the oxidative stress and inflammation in 
patient with essential hypertension. Hypertension, 1998; 921-928.

21. Minuz, P., Fava, C., \&Lechi, A. Lipid peroxidation, isoprostanes and vascular damage. Pharma. Reports, 2006;57-68.

22. Shi GP, Sukhova GK, Grubb A, Ducharme A, Rhode LH, Lee RT, et al. Cystatin C deficiency in human atherosclerosis and aortic aneurysms. J Clin Invest 1999;104:1191-1197.
23. Shankar A, Teppala. S Relationship between serum cystatin $\mathrm{C}$ and hypertension among US adults without clinically recognized chronic kidney disease. J Am Soc Hypertens. 2011 Sep-Oct;5(5):378-84.

24. Kestenbaum B, Rudser KD, de Boer IH, Peralta CA, Fried LF, Shlipak MG, Palmas W, Stehman-Breen $\mathrm{C}$, Siscovick DS. Differences in kidney function and incident hypertension: the multi-ethnic study of atherosclerosis. Ann Intern Med. 2008 Apr 1;148(7): 501-8.

\section{How to cite this article?}

Sumapreethi A, Bhaskar M V, Babu K J, Madhulatha M. Association of Serum Lipids, Oxidative Stress and serum Cystatin C with Prehypertension and Hypertension. Int J Med Res Rev 2014;2(4):349- 354. doi:10.17511/ijmrr.2014.i04.12 